\title{
Ethical analysis on application of Massive Open Online Courses (MOOC): Concept, Necessity and Methodology Jie Xiong ${ }^{1, a^{*}}$, Long-Can $\mathrm{Wu}^{2, \mathrm{~b}^{*}}$
}

${ }^{1}$ School of Electronics and Information, Yangtze University, Jingzhou, China

${ }^{2}$ Sichuan Thinkers Research Center, Yibin University, Yibin, China

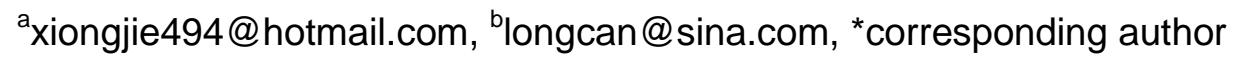

Keywords: Massive Open Online Courses(MOOC); Ethical analysis; Education technology; Technology ethics

\begin{abstract}
The massive open online courses(MOOC) has been introduced into China recent years. It has the advantages of convience and free. However, it is seldom analyzed on the perspctive of ethics. The history of MOOC is introduced briefly first. Then the concept, necessity, and methodology is discussed in this paper. Finally, the conclusion is drawn that MOOC should be used more scientifically and reaonably on the basis of ethical study.
\end{abstract}

\section{Introduction}

The concept of Massive Open Online Courses (MOOC)[1] is proposed by Bryan Alexander and Dave Cormier in 2008, and it has been widely spreaded all over the world since 2012, when is called the primary era of MOOC. MOOC is composed by many learners who are willing to share and cooperating with each other for more kownledge. It is suitable for the learning models of experts training, learning and intercourse from multidiscipline, and special education. It has significant influence on the higher education and attacts the attention of higher educational circles. The questions rased up when the MOOC is becoming popular, such as "how about the validity of MOOC?", "how to master the boundary of MOOC?", and "how to use MOOC to imporve our educaitonal quality?". All these questions will not be answered unless we analyze the MOOC at the perspective of ethics.

\section{History of MOOC}

Education is an essential tool for individuals and society to solve the challenges of the present and seize the opportunities of the future. However, the current provision of education is limited by educational institutions' capacity, consequently, this resource is available to the few, not the many. The digital revolution offers a potential solution to these limitations, giving a global audience unprecedented access to free, open and high-quality educational resources[2].

The University of Phoenix began offering online degree programs in 1989 and awarded degrees to its first online class of MBA students in 1991[3]. James J. O'Donnell, a Professor at Georgetown University, offered an online semina in 1994[4]. In 1999, MIT Faculty considered how to use the Internet in pursuit of MIT's mission - to advance knowledge and educate students - and in 2000 proposed OCW. MIT published the first proof-of-concept site in 2002, containing 50 courses. By November 2007, MIT completed the initial publication of virtually the entire curriculum, over 1,800 courses in 33 academic disciplines. Going forward, the OCW team is updating existing courses and adding new content and services to the site[5]. The Open Educational Resources(OER), which was set up in 2002 by United Nations Educational, Scientific and Cultural Organization, provides educational materials that are in the public domain or introduced with an open license[6]. The Open Courseware Consortium (OCWC) was set up in 2005[2]. After then, OCW-Universia at Spain, the African Virtual University, Japan OpenCourseWare Consortium, Korea OpenCourseWare Consortium, are set up respectively. 
The term MOOC was coined in 2008 by Dave Cormier of the University of Prince Edward Island in response to a course called Connectivism and Connective Knowledge (also known as CCK08). CCK08, which was led by George Siemens of Athabasca University and Stephen Downes of the National Research Council, consisted of 25 tuition-paying students in Extended Education at the University of Manitoba, as well as over 2200 online students from the general public who paid nothing[7,8].

\section{Concept of MOOC ethics}

The MOOC ethics studies how to guide, constrain, and regular the concept, behaviors, actions, and standards to fullfil the moral ethics of oneself and outer sciety, in the circustance of MOOC. The MOOC ethics is belong the concepts of network educaiton technology ethics, which is associated with the ethics, education, and network, illustrated in the Figure 1.

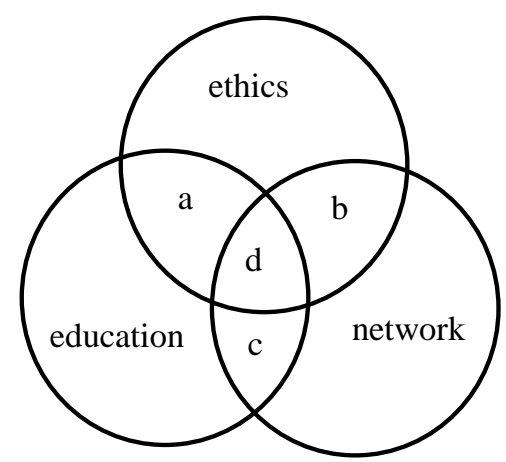

Figure. 1 The relationship between ethics, education, network, and MOOC ethics a. education ethics; b. network ethics; c. network education, such as MOOC; d. MOOC ethics.

The relationship between MOOC ethics and other related disciplines, according to [9], is illustrated in Figure 2..

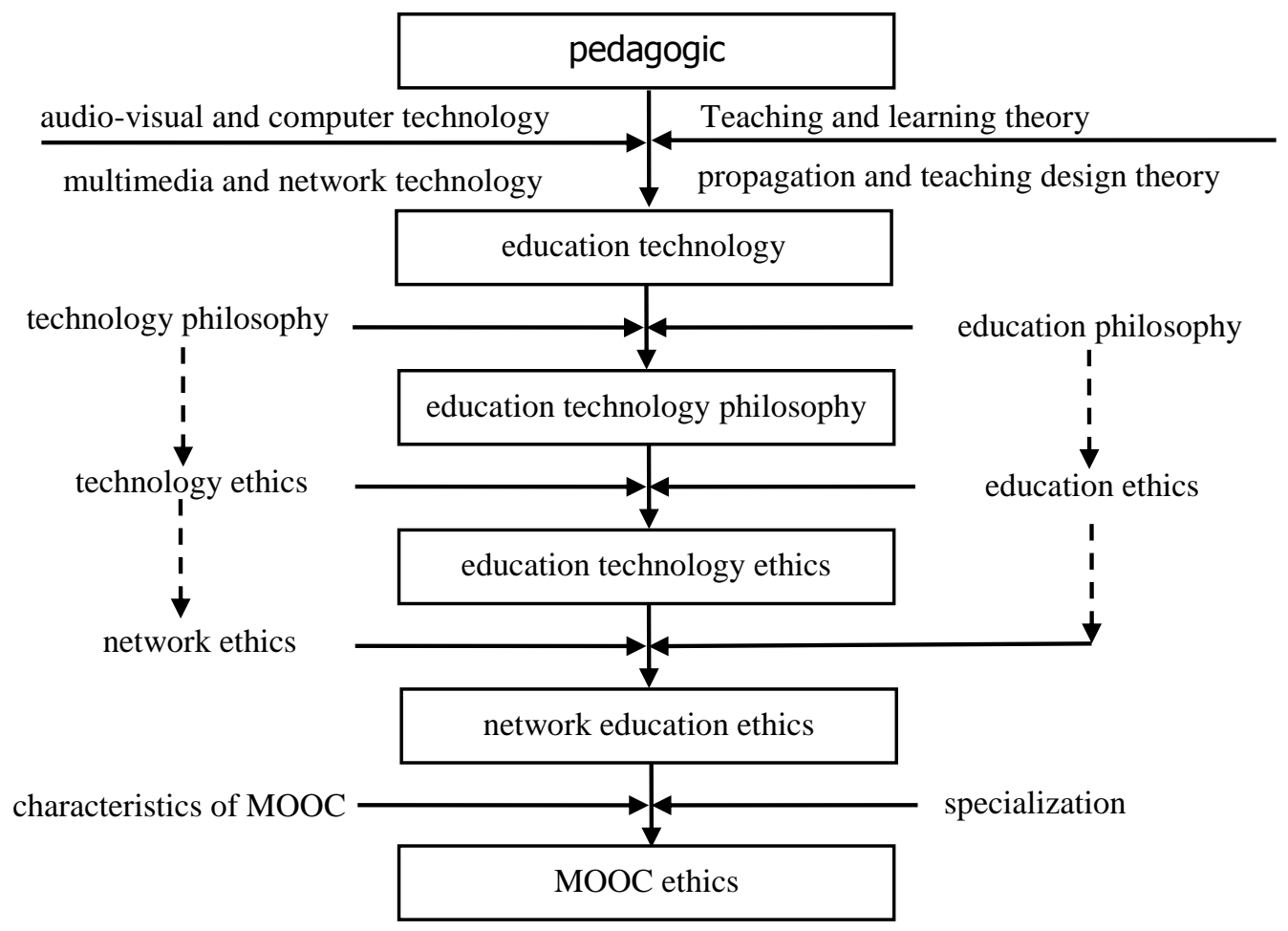

Figure. 2 Relationship between MOOC ethics and other disciplines 


\section{Necessity of ethical analysis on MOOC}

Although the MOOC help us study more convient and freedom, it may be halmful to us if ti is used inappropriate. We should analze MOOC at the perspective of ethics to help us use it better[10].

On the one hand, the ethical problems were appearing constantly. Firstly, MOOC may lead to the cheating of learning process and result, for the it is open and free. The teachers and students are saparated each other. The restriction of learning time and the learning task needed finished can not be supervised easily, comparing to the traditional courses. Students may just browse the website, click the mouse, or copy and paste. The cheating action can ruin the learning quality, spoil students and even influent their characteristics. Secondly, the saparation of teachers and students brought by MOOC may cause emotion confusion between teachers and students. MOOC can not form the closing relationship between teachers and students who are in the traditional face to face teaching situation, although it can overcome the restriction of time and space and provide interaction means with the help of information technology. Thirdly, the abundant network resources let the students of MOOC faced to the ethical challenges. There are so many bad informations on the internet, due to the openness and anonymity of network. The bad informations bring the ethical challenges to the partners of the MOOC, althought most of them can filtered by the enhanced network security technology, such as firewall, information filtering.

On the other hand, the nonstandard morality problems are serious. Firstly, nonstandard of emotional communication between teachers and students on MOOC is seriously. There are small part of teachers, illustrated in the table 1,2 (according to [11]), fall into the misunderstanding of emotional communication during teaching, due to the usage of IT equipment. Secondly, the worship of technology caused the nonstandard of teaching. Some teachers worship the educational technology leading to the behavior alienation. When the educational technology and tools are treated as the universal tool and the education itself is forgotton, the nonstandard problems come out. Thirdly, the adverse motivations cause the nonstandard of teaching. Some educational technology are used not for the convient of education, but for the some outter pressures.

Table 1 Statistics of whether or not teacher can master the communication with students when the IT equipment is used[11]

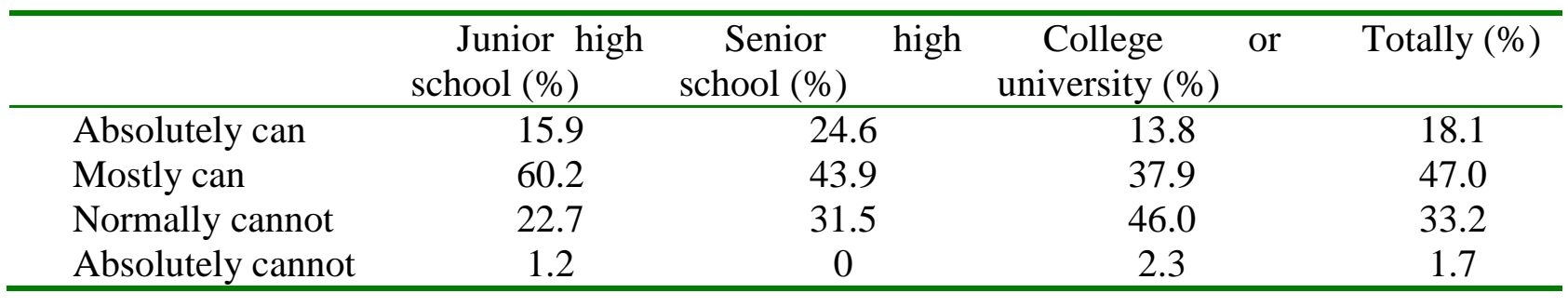

Table 2 What kind of response of the teacher when students ask for help or communication by network during the network education[11]

\begin{tabular}{|c|c|c|c|c|}
\hline & $\begin{array}{c}\text { Junior high } \\
\text { school }(\%)\end{array}$ & $\begin{array}{l}\text { Senior high } \\
\text { school }(\%)\end{array}$ & $\begin{array}{r}\text { College or } \\
\text { university }(\%)\end{array}$ & $\begin{array}{l}\text { Totally } \\
(\%)\end{array}$ \\
\hline Quick response, obvious effect & 38.4 & 31.9 & 9.7 & 26.7 \\
\hline Quick response, limited effect & 15.2 & 23.0 & 21.3 & 19.8 \\
\hline Slow response, limited effect & 23.2 & 23.9 & 49.0 & 32 \\
\hline No response & 23.2 & 21.2 & 20.0 & 21.5 \\
\hline
\end{tabular}




\section{Methodology of Ethical analysis on MOOC}

Three theory tools of ethics can be used to ethical analysis on MOOC: teleology, deontology, and theory of virtue[12]. The Teleology is to adjudge the Good-or-Evil in Ethics according to the aim and result of behavior. The deontology, which is different from the teleology, is to adjudge the Good-or-Evil in Ethics according to the motivation, and whether the behavior is in keeping with duty, obligation, responsibility. The theory of virtue, which is beyond the teleology and deontology, is centralled with what is the characteristics a man should have.

The three theories have advantages and disadvantages all. We can comprehensively apply these three theories to evaluate ethically to the application of MOOC, which illustrated in Figure 3 according to [13]. For Exaplem, teachers may use different evaluation system and training target if they take the different ethical position, when teachers evaluate the students' learning behaviors and achievements. On one hand, it will cause the network education to be examination-oriented, if teachers, following Teleology, do not pay attention to the learning process and method but look at the last acquired skills and test scores; On the other hand, the teachers following the deontology regard the learning as the duty of student, and evaluate the students by learning process and attitude rather than by examination scores; Howerver, the teacher following the theory of virtue regart culturing the students' morality, learning ability and good learning behavior as the main object of network education. From the example we can see that different ethical standpoint will lead to different network education pattern and different teaching evaluation system.

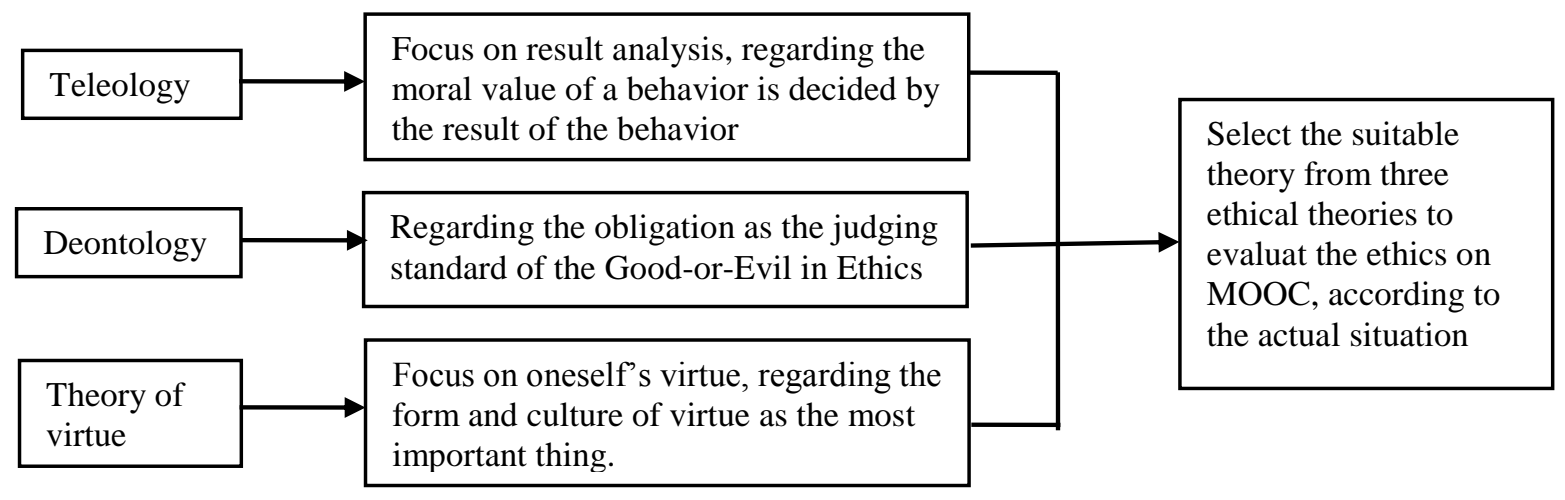

Figure 3 Logical frame graph of Ethical analysis on application of MOOC[13]

\section{Summary}

The MOOC is popular in modern education. There are few study focus on the ethical analysis on application of MOOC. The concept, necessity and methodology of the ethical analysis on application of MOOC is studied in this paper. It is important to use the MOOC more scientifically and reasonably after the application of MOOC in the basis of ethical study.

\section{References}

[1] X.G. Chen and D.M. Wang, On the Development Process and Main Characteristic of MOOC (in Chinese)[J], Modern educational technology, Vol. 23 (2013) No.11, p.5.

[2] Information on http://www.oeconsortium.org/

[3] Information on http://www.phoenix.edu/about_us/media-center/just-the-facts/online-education.html.

[4] Information on http://faculty.georgetown.edu/jod/texts/rsn.html

[5] Information on http://ocw.mit.edu/index.htm

[6] Information on http://www.unesco.org/new/en/communication-and-information/ access-to-knowledge/open-educational-resources/

[7] Information on http://en.wikipedia.org/wiki/Massive_open_online_course 
[8] L.L. Zhao, K.Y. Zhao and F.G. Hu, The Analysis on the Present Situation and Trend in the Field of the MOOC Research in China (in Chinese)[J], Modern educational technology, Vol. 24 (2014), No.12, p.12.

[9] J.N. Zhang, H.L. Li and X.Y. Li, On the ethics of oline education: and exploration from the ethical point of view (in Chinese)[J], Open education research, Vol. 17 (2011) No.4, p.53.

[10] Y.D. Xing and W.H. Hou, Research on anomie and development strategies of online education from the perspective of information ethic (in Chinese)[J], CHINA MEDICAL EDUCATION TECHNOLOGY, Vol. 27 (2013) No.2, p.177.

[11] G.Y. Liu, Survey on the morality disorder in the educational technology practice at school and the study of its strategies ( MS. Hunan normal university, China, 2006), p.17.

[12]Y.H. Lv: Information Ethics (Central South University Press, China, 2002).

[13]J. Xie, Ethical analysis on application of modern educational technology: necessity and research logic (in Chinese) [J], e-Education Research, (2012) No. 10, p.23. 